\section{EMBRYRIDDLE \\ Aeronautical University}

SCHOLARLY COMMONS

\section{International Journal of Aviation,} Aeronautics, and Aerospace

\title{
Urban flow and small unmanned aerial system operations in the built environment
}

\author{
Kevin A. Adkins \\ Embry-Riddle Aeronautical University, adkinsk@erau.edu
}

Follow this and additional works at: https://commons.erau.edu/ijaaa

Part of the Aerodynamics and Fluid Mechanics Commons, Atmospheric Sciences Commons, Aviation Safety and Security Commons, Navigation, Guidance, Control and Dynamics Commons, Other Aerospace Engineering Commons, and the Other Oceanography and Atmospheric Sciences and Meteorology Commons

\section{Scholarly Commons Citation}

Adkins, K. A. (2019). Urban flow and small unmanned aerial system operations in the built environment. International Journal of Aviation, Aeronautics, and Aerospace, 6(1). https://doi.org/10.15394/ ijaaa.2019.1312

This Article is brought to you for free and open access by the Journals at Scholarly Commons. It has been accepted for inclusion in International Journal of Aviation, Aeronautics, and Aerospace by an authorized administrator of Scholarly Commons. For more information, please contact commons@erau.edu. 


\section{Introduction}

The Federal Aviation Administration (FAA) put forth a set of regulations (Part 107) in August of 2016 that govern small unmanned aerial system (sUAS) operations. These regulations restrict unmanned aircraft (UA) from flying over people, beyond visual line of sight (BVLOS), and, while cargo transport is authorized, put forth that the transportation of cargo cannot cross state lines nor can objects be dropped in any manner that presents a hazard to people or property. However, the recently signed FAA Reauthorization Act of 2018 directs the FAA to update their regulations enabling the carriage of property by sUAS by October of 2019. Furthermore, the Act prioritizes the development of regulations that open up sUAS operations to BVLOS and over people. Consequently, as sUAS technology and regulations continue to evolve, and the industry matures, applications for sUAS will continue to expand. Many of these applications will take place in urban environments. Applications presently envisioned in the urban environment include urban air mobility, package delivery, infrastructure inspection, and intelligence, surveillance and reconnaissance (ISR), to name a few.

Weather is a key factor in day-to-day manned aviation operations, a factor that still challenges every facet of manned operations: pre-flight planning, flight, and post-flight analysis. Likewise, weather must be considered in every facet of sUAS flight planning and operations. However, forecasting products are not currently specifically produced for sUAS operators. To date, operators have been able to sufficiently 'forecast' for themselves by visually inspecting the immediate area due to the present obligation of maintaining visual line of sight (VLOS) with the UA and the ability to promptly recover the UA if needed. The role of weather in sUAS flight planning will become more important as unmanned aerial systems (UAS) range and autonomous capabilities increase, and BVLOS operations become more common place. Exacerbating this pre-flight challenge, in flight sUAS operators, being detached from the UA, may have more limited knowledge of the current state of the atmosphere and, over the long-term, may not develop the same basis of experience and intuition for aviation weather. Further, upon completion of the mission, a lack of proper consideration of the weather may manifest in post-flight analysis through degraded sensor measurements.

Similar to manned aircraft, UA operations are impacted by low ceilings and visibility and both types of operators must respect cloud clearance requirements. Variations in temperature, pressure, and humidity change the density altitude and, consequently, the performance of both types of vehicles, albeit extreme temperatures can uniquely reduce battery life, and consequently flight time, for UA. However, in contrast to manned aircraft, UA, due to their lower mass and moment of inertia, are disproportionality impacted by 
atmospheric wind and turbulence. Wind and turbulence can, to a greater extent, affect the stability of an UA, and therefore the quality of a measurement from an aircraft mounted sensor, endurance of an UA, the ground speed of the vehicle and, possibly, the ability to successfully control or recover the aircraft. Winds and turbulence can decrease the endurance of an UA as it works to stabilize itself or increase the platform's endurance as it exploits updrafts. Extreme updrafts and downdrafts can result in a failure to deconflict the UA with fixed objects or vertically separated aircraft. Hence, because of the disproportionate affect that wind and turbulence have on sUAS, and the likelihood of increased urban operations, this paper first reviews how turbulence affects an UA. Subsequently, it explores a diverse body of literature regarding urban studies for pedestrian comfort, the available wind resource for small building mounted wind turbines, urban canopies and canyons, building design and construction, urban heat islands, and air pollution and dispersion. Relevant insight from these studies to sUAS urban operations is consolidated and discussed.

\section{Affect of the Environment on sUAS}

sUAS operations, including urban operations, take place in the atmospheric boundary layer (ABL), a layer of air typically hundreds of meters to a few kilometers in thickness immediately adjacent to the Earth's surface. The $\mathrm{ABL}$ is a very different environment than that in which manned aircraft operate. The ABL is the part of the atmosphere that is directly influenced by the Earth's surface and quickly responds to surface forcings (Stull, 1988). Turbulent motions on a time scale of an hour or less are an important process in the ABL and turbulence's nearly ubiquitous presence can also be used to differentiate the ABL from the remaining free atmosphere. While winds in the free atmosphere are geostrophic, winds in the ABL are subgeostrophic and the speed often follows a logarithmic vertical profile as friction at the Earth's surface causes the wind speed to slow. It is often instructive to analyze the wind, U, by breaking it apart into a mean, $\bar{U}$, and fluxuating, $u^{\prime}$, component as expressed in Equation 1 and illustrated in Figure 1. The high frequency fluxuating component represents turbulence and can more easily be thought of as a gust that is superimposed on the mean wind.

$$
U=\bar{U}+u^{\prime}
$$




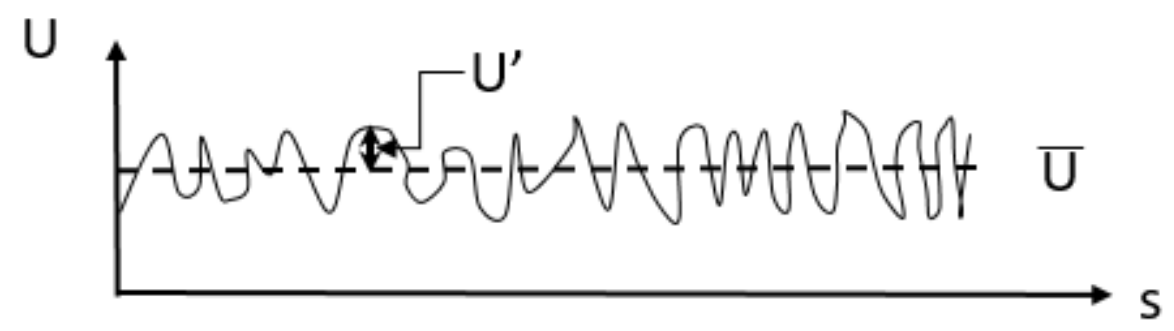

Figure 1. A representative wind speed trace showing a high frequency fluctuating component, representing turbulence, that is a deviation from the mean wind speed. This deviation is at times greater and at other times less than the mean wind speed.

sUAS fly at much lower speeds than their manned counterpart, more comparable to the mean wind speeds found in the ABL. Obviously, too high of a mean wind speed may make it impossible for the sUAS to navigate as desired, e.g. make forward progress. Turbulence intensity, $I$, is defined in Equation 2 as the square root of the variance of the fluxuating velocity component nondimensionalized by the mean wind speed. With a decrease in the mean wind speed as you approach the ground, turbulence intensity will generally increase as altitude decreases. For the same reason, the turbulence intensity that an UA perceives decreases with increasing flight speed (Mohamed, Massey, Watkins, \& Clothier, 2014; Watkins, Milbank, Loxton, \& Melbourne, 2006; Watkins, Thompson, Loxton, \& Abdulrahim, 2010). Therefore, as the mean relative velocity of the UA increases the relative turbulence intensity for the vehicle decreases. Walshe (1972) put forth that turbulence intensity can be greater than $15 \%$ at low altitudes in suburban environments. While a turbulence intensity of $30 \%$ is typically assumed for urban landscapes, Roth (2000) has shown that turbulence intensities greater than $40 \%$ can be found in city centers within tens of meters of the surface and $I$ can obtain values greater than $50 \%$ in city centers with high-rise buildings. Supporting observations have also shown that, for a given height above the ground, turbulence intensity can be two times greater in an urban environment than a rural one (Bowne \& Ball, 1970; Roth, 2000).

$$
I=\frac{\sqrt{\overline{u^{2}}}}{\bar{U}}
$$

Turbulence is both thermally and mechanically generated. Surface heating and an unstable environment can create thermal turbulence. The increased shear production in urban canopies, along with the higher heat capacity of urban surfaces (asphalt and concrete), anthropogenic flux, and radiation trapping by 
structures can, in general, reduce atmospheric stability in this setting (Zajic et al., 2011). Thermal effects play a more dominant role when atmospheric winds are low. Therefore, while such winds may not be a limiting case for sUAS operations, thermal instability can contribute to increased turbulence intensity that does impact operations (Watkins et al., 2010). Since different surfaces heat unequally, thermal turbulence can vary significantly in an urban environment where extreme surface heterogeneity is found.

Under most stability conditions found in an urban environment, the generation of turbulence is predominantly mechanical in nature (Rafailidis, 1997). Mechanical turbulence stems from wind shear brought about by surface friction, two adjacent layers of air moving in different directions, or flow past an obstacle. Consequently, while large buildings, trees, and other structures can decrease the mean wind speed in an urban environment (Figure 2), these structures contribute to the creation of mechanical turbulence by all three mechanisms. As the streamwise flow is disturbed by these roughness elements it is perturbed to-andfro and, respecting continuity, cross stream and vertical turbulence is generated. However, unlike turbulence in the horizontal plane, the magnitude of vertical turbulence is inhibited by the ground. Consequently, a representative ratio for streamwise, cross flow and vertical turbulence over a rough surface is: 1: 0.8: 0.5 (Lissaman, 2009). Hence, turbulence in close proximity to the ground is anisotropic. In the absence of a significant synoptic wind, local circulations, analogous to sea-breezes and similarly driven by thermal gradients between two different landscapes, can still induce flow through cities that gives rise to turbulence.

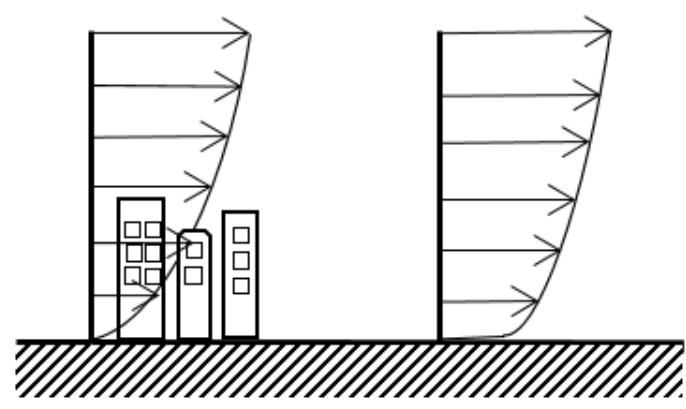

Figure 2. Representative wind profiles for an urban and rural landscape. Note how the wind profile for a rural landscape is more full near the ground.

The mechanical turbulence generated in the wake of urban structures spans a wide variety of length scales with the largest eddies commensurate with the size of the structure (Marino et al., 2015; Mohamed, Carrese, Fletcher, \& Watkins, 2015). Due to the size of these large eddies relative to the characteristic 
dimensions of sUAS, these eddies can be taken to be effectively stationary relative to the sUAS. However, eddies on the other end of the spatial spectrum are more comparable to the characteristic dimensions of sUAS and, as a result, are responsible for the destabilization of the UA (Mohamed, Massey, et al., 2014). These smaller eddies are also associated with smaller temporal scales and, consequently, turbulence with temporal scales on the order of tens of seconds or less are of greatest interest for sUAS (Mohamed, Clothier, et al, 2014; Watkins et al., 2010).

While fixed-wing aircraft can more efficiently cover a larger geographical distance, multirotor UAS have the ability for vertical takeoff and landing (VTOL), hover, and greater maneuverability. Consequently, it is anticipated that multirotor UAS will dominate urban operations. Fortunately, flight testing has demonstrated that multirotor aircraft are less susceptible to the effects of turbulence than their fixed-wing counterpart and that piloting difficulty scales less with multirotors, compared to fixed-wing air vehicles, when turbulence levels increase (Loxton, Abdulrahim, \& Watkins, 2008; Watkins et al., 2010). While comparisons such as these must obviously take place between UA with comparable mass and moment of inertia, it should be kept in mind that effective turbulence intensity will decrease, as described above, for a fast rotating rotor blade compared to a slower moving fixed-wing (Watkins et al., 2010). Regardless, flight testing has also demonstrated that the high frequency of control inputs required in highly turbulent conditions can exceed even the capability of experienced pilots for both multirotor and fixed-wing UA (Loxton et al., 2008; Watkins et al., 2010). As a result, improvements in disturbance rejection strategies continue to be investigated (Sydney, Smyth, \& Paley, 2013b; Szczublewski, 2012; Tran, Bulka, \& Nahon, 2015; Yeo, Sydney, \& Paley, 2016).

The aforementioned advantages that multirotor UA afford can be enhanced or tempered by the aircraft's disk loading. Analogous to wing loading, defined as the aircraft's weight divided by its wing area, disk loading divides the multirotor's weight by the area swept out by its rotors. Increasing the diameter, or number, of rotors decreases the overall disk loading by increasing the rotor swept area. This improves efficiency and, consequently, the UA's hover performance and endurance. However, a low disk loading increases the UA's susceptibility to turbulence as the instantaneous gust velocity moves closer to the induced velocity of the rotor (Thompson, Watkins, White, \& Holmes, 2011). The corresponding large rotor diameters associated with a low disk loading also offer an increased rotational inertia and increase the overall size of the UA (Kennedy, Fisher, Wang, $\&$ Palmer, 2017). Therefore, multirotor design must straddle the desire for efficient performance with the higher disk loadings that afford multirotors the stability in turbulence that are so attractive for urban operations (Prudden et al., 2018). 
Previous investigations indicate that both multirotors and fixed-wing sUAS are most sensitive to atmospheric disturbances about the longitudinal axis (roll) compared to the lateral (pitch) or vertical (yaw) axes (Thompson, 2012; Watkins et al., 2010). Analysis of the disturbance rejection capability of multirotors about each of the three axes indicate that multirotor are best equipped to reject a vertical disturbance. In such a scenario, all actuators (motors) are in line with the disturbance and hence deal with it most effectively. However, correcting from this type of disturbance is the most energy intensive form of correction as thrust must be produced by all rotors. All other perturbations are corrected for by differential thrust acting in conjunction with a moment arm and are therefore less energy intensive (Szczublewski, 2012).

The mean wind impacts multirotors both through frame drag (Chen, He, \& Zhou, 2013; Sydney et al., 2013a) and by setting the angle of the flow approaching the propellers. The horizontal component of this flow into the spinning rotor disk creates a force and corresponding moments that most significantly impact a multirotor's motion (Tran et al., 2015). However, under identical flight conditions, translational accelerations of an unmanned helicopter have been found to be roughly half that of a fixed-wing UA with rotational accelerations less than one-third (Watkins et al., 2010).

Fixed-wing UA's susceptibility to rolling moments is brought about by spanwise variations in angle of attack and velocity (Abdulrahim, Watkins, Segal, Marino, \& Sheridan, 2010; Etkin, 2005; Mohamed, Clothier, Watkins, Sabatini, \& Abdulrahim, 2014; Mohamed, Massey et al, 2014; Nelson, 1998; Stevens \& Lewis, 2003; Watkins et al., 2006). Inspection of the basic lift equation, given in Equation 3 where $L$ represents the force of lift and $S$ the wing planform area, show that, neglecting any changes in air density, $\rho$, that might be brought about by turbulence, only changes in velocity, $v$, or the lift coefficient, $C_{L}$, change the amount of lift produced.

$$
L=C_{L} \frac{1}{2} \rho v^{2} S
$$

Thompson et al. (2011) sampled ABL flow over open terrain with four multi-hole pressure probes, spaced $0.15 \mathrm{~m}$ apart, and showed that for mean wind speeds between $5 \mathrm{~m} / \mathrm{s}$ and $7 \mathrm{~m} / \mathrm{s}$, that longitudinal velocity differences as great as $2.5 \mathrm{~m} / \mathrm{s}$ existed between adjacent probes observed over a $0.1 \mathrm{~s}$ period of time. Over the same time period, pitch differences, that bring about changes to the value of the lift coefficient, as great as 30 degrees were concurrently observed. One can presume that urban flow would offer even greater perturbations. Each of these fluctuations within the span of the wing lead to differential lift forces across the wingspan with changes in pitch angle bringing about the greatest difference, especially as UA flight speed increases (Thompson \& Watkins, 2010; Thompson 
et al., 2011; Watkins et al., 2006). The magnitude of the resulting roll depends on the relationship between the wavelength of the turbulence and the wingspan of the UA with wingspans approximately equal to one-half the turbulent gust wavelength experiencing the greatest roll response. In this scenario, one wingtip will contend with an updraft while the other wingtip experiences an accompanying downdraft. Turbulence with much smaller temporal or spatial scales will balance out across the span (Lissaman, 2009). Hence, sUAS are rather impervious to large gusts but must contend predominately with smaller gusts. While a more massive sUAS or one with a higher moment of inertia may help mitigate the resulting linear accelerations, angular roll rates, or the required rapidity of control input brought about by these flow perturbations, flight test has shown that the associated correcting input must be larger (Abdulrahim et al., 2010).

\section{Urban Flow Features Relevant to UAS Operations}

UAS urban operations will take place within a unique portion of the ABL referred to as the urban boundary layer (UBL). Even though the footprint and adjacent surroundings of every urban area is unique and the conditions differ on a diurnal basis and with synoptic set up, the UBL can be appropriately characterized by dividing it into two broad vertically stacked regions. The lowest layer, the roughness sub-layer (RSL), can be modeled by an exponential vertical velocity profile that is highly influenced by urban roughness elements that give rise to turbulence that is neither spatially nor temporally uniform. Above this region exists the inertial sub-layer (ISL) with a logarithmic vertical velocity profile (Heath, Walshe, \& Watson, 2007) and turbulence that is more homogeneous and fluxes that are constant (Ching, 1985; Roth, 2000; Schmid, Cleugh, Grimmond, \& Oke, 1991). Contained within the RSL is the urban canopy layer (UCL) that stretches from the ground to the roof level of the highest buildings. The UCL dynamic is driven by surface shear at the ground, strong shear at the rooftop level, building wakes, and convection (Clarke, Ching, \& Godowich, 1982; Heath et al., 2007; Rotach, 1993a/b). The intense shear that is formed by the building tops convert the kinetic energy of the mean flow into turbulent kinetic energy and, in conjunction with wakes and urban canyons, results in high turbulence intensities (Thompson et al, 2011). High turbulence intensities present operational challenges to UA flight control and stability, accurate position holding, and the avoidance of collisions with structures. The effect of building dimensions, spacing, orientation and density on the mean flow and turbulence generation are explored in the remainder of the paper. 


\section{Flow Around a Single Building}

An object obstructing flow can be characterized as a streamlined or bluff body. Flow around a streamlined body has minimal flow separation and, consequently, the flow is dominated by frictional drag; flow around a bluff body, due to its sharper edges, results in substantial flow separation and hence is dominated by pressure drag. The amount of pressure drag is strongly associated with the cross-sectional area of the body (Anderson, 2017). When flow encounters a building, a bluff body, the disturbed flow can, in general, be partitioned for analysis into four distinct zones: the frontal zone where the flow approaches the building, a zone over the roof, the downwind wake zone, and lateral zones to either side of the building. For both isolated buildings and dense building configurations, it has been observed that disturbed flow exists vertically until a height approximately three times greater than the physical height of the tallest structure (Erell, Pearlmutter, Williamson, \& Williamson, 2015; Mohamed, Carrese et al., 2015; Rafailidis, 1997).

The induced flow around a building is driven by two distinct pressure gradients. The first pressure gradient is created by a stagnation point for the impinging upstream flow that creates an area of relatively high pressure on the face of the building. Typically, this stagnation point is located near the centerline on the upper portion of the building (Abohela, Hamza, \& Dudek, 2013). From this point, a portion of the flow is deflected upward and over the building while, to a greater extent because of the positioning of the stagnation point, flow is directed down the front face of the building (Erell et al., 2015). The updraft region in front of the building has been shown to be a region of reduced turbulence and an area suggested for sUAS orographic soaring that would extend the endurance of the UA (Abohela et al., 2013). The downward flowing air creates a bolster eddy that results in a region of reverse flow and lower wind speed near the base of the building. Within the approach to the building, two discrete low wind zones have been identified, one far-field and one near-field with respect to the building. Wind tunnel tests by Tsang, Kwok, and Hitchcock (2012) showed that the far-field low wind speed zone moves further upstream as the obstructing building height increases, presumably due to the enhanced downwash on the larger building face, while the location of the near-field low wind zone is invariant to building height. An increase in building width resulted in a similar dynamic (Tsang et al., 2012).

In addition to the flow induced up and down the face of the building, flow is also deflected laterally around the sides of the building. Flow around a bluff body such as this is highly separated. The low pressure associated with the separated flow on the side, along with downwind of the building, creates a second pressure gradient influencing the flow around the building as air moves from an area of higher to lower pressure. The pressure differential between the relatively 
high pressure on the windward face of the building and the lower pressure found around corners and over roof lines can greatly accelerate the flow around the building. The low pressure associated with the separation further creates suction and regions of reverse flow and turbulent eddies on the other three sides of the building. However, the presence of any openings that allow for the injection of higher speed flow, such as an open archway, can mitigate the separation and associated disturbed flow (Zajic et al., 2011).

In general, the low-pressure region found in the downstream wake of a building sets up two distinct secondary circulations around horizontal axes near the surface. These mirror circulations are driven by flow around either side of the building being drawn into the low-pressure region on the lee of the building. This region of separated flow is characterized by lower wind speed but higher turbulence. Wind tunnel studies have shown that the size of this near-surface low wind speed region decreases with an increase in building height as the higher building height directs more flow around, versus over, the building (Lawson, Snyder, \& Hunt, 2002; Tsang et al., 2012). Thus, the greater volume of air moving around the building enhances the flow on the lee of the building. To the contrary, aloft, the reattachment length for the leeside separated flow near the top of a tall building increases with building height. These distinctly different outcomes are the result of the recirculation area aloft not reaching the ground and interfering with the surface backflow area (Abohela et al., 2013). In the same wind tunnel study, turbulence intensity, as might be anticipated, was also observed to scale with building height.

\section{Flow Surrounding a Group of Buildings}

An urban canopy is characterized by multiple tall buildings and may bring about an increase or decrease in surface winds, localized pockets of accelerated or separated flow at the roof level, the enhancement or diminishment of turbulence, or any combination thereof. When the ratio of building height, $\mathrm{H}$, to building spacing in the direction of the prevailing flow, $\mathrm{W}$, is greater than $0.3-0.5$, i.e. an aspect ratio of $\mathrm{H} / \mathrm{W}$, the closely spaced buildings can affect the previously described flow around a single building (Counehan, 1967; Hosker, 1979; Hussain \& Lee, 1980; Oke, 1987; Raupach, Thom, \& Edwards, 1980; Zajic et al., 2011). Building configurations with an aspect ratio smaller than 0.3-0.5 can be taken as a collection of isolated buildings (Erell et al., 2015). Flow over building configurations with an aspect ratio between 0.5-0.65 is characterized by a wake interference regime (Hussain \& Lee, 1980; Oke, 1988). In this flow regime, the eddies to the lee of the upwind building are reinforced by the downward deflection of air on the windward face of the downwind building. Hence, the bolster eddy associated with the upwind building works synergistically with the 
upwind building's lee eddy to further increase turbulence. This recirculating flow between the buildings is neither steady nor uniform since the downflow on the downwind windward face is typically more concentrated and stronger compared to the weaker and more expansive upflow on the lee wall (Britter \& Hanna, 2003). Despite the enhanced circulation and turbulence, associated wind speeds are overall lower for this regime (Erell et al., 2015). Flow for more closely spaced buildings, with an aspect ratio greater than 0.65, is described as a skimming flow regime (Hussain \& Lee, 1980; Oke, 1988; Zajic, Fernando, Brown, \& Pardyjak, 2015). Here, a more stable vortex is established within the inter-building space by a downward momentum transfer but, the majority of the flow 'skims' over the canyon space. Consequently, the canyon space, overall, contains weak winds with the most robust velocity components at the bottom of the canyon oriented upward and toward the lee wall (Britter \& Hanna, 2003). The differentiation between these flow regimes was established by wind tunnel investigations for infinitely long rows of buildings. More realistically, when rows of buildings with finite length are considered, the previously delineated transitions defined by the aspect ratio $\mathrm{H} / \mathrm{W}$ are slightly lowered when the ratio of building length, $\mathrm{L}$, to building height, H, i.e. L/H, drops below 2 (Oke, 1988). Furthermore, for all regimes, a building array with a lower aspect ratio has a wider and more robust reverse flow region within the inter-building spacing compared to an array defined by a higher aspect ratio (Abd Razak, Hagishima, Ikegaya, \& Tanimoto, 2013).

While urban flow is complex, a useful estimate for the relationship between the prevailing canopy flow aloft and the wind speed observed within an underlying urban canyon has been put forth as:

$$
u_{c}=u_{r} \mathrm{P}
$$

where $u_{c}$ is the horizontal wind speed in the middle of the canyon, $u_{r}$ is the speed of the prevailing flow above the canyon's buildings, and $\mathrm{P}$ is a diminution factor that is dependent on: the aspect ratio, $\mathrm{H} / \mathrm{W}$, of the canyon, the height of the associated wind measurements, and the angle of the prevailing wind direction relative to the canyon axis (Erell et al., 2015). Multiple studies (Britter \& Hanna, 2003; Pearlmutter, Berliner, \& Shaviv, 2005) have put forth a value of P ranging from 0.5 to 0.35 for flow with a nearly parallel approach angle toward a wide and narrow canyon respectively. At the same time, an accompanying drop of turbulence levels on the order of $10 \%$ was also observed for this scenario. A further attenuation of the flow speed represented by a decrease in $\mathrm{P}$ to 0.25 has been observed for prevailing flow that approaches the canyon in a perpendicular manner. Thus, the attenuation of canyon winds increases with greater crossing angles, greater overall surface roughness, or narrower canyons. A value for $\mathrm{P}$ 
equal to 0.25 , for example, represents a three-quarter reduction in the magnitude of the wind speed.

For intermediate approach angles between 0 and 90 degrees, a region of recirculation, along with a street flow component, should be anticipated in the canyon (Britter \& Hanna, 2003). Aggregate flow patterns, such as these, have been successfully described, as one might expect, from the vector sum of the disparate velocity components. This insight can provide a useful strategy for anticipating dynamic and complex flow in a canyon and elsewhere.

When a significant difference in height exists between two adjacent buildings, the associated flow can be especially complex. In general, when a shorter building is positioned behind a significantly taller one, the wake of the taller, windward building dominates the entire wake structure and can overpower any recirculation regions associated with the shorter building (Hunt \& Carruthers, 2004). When the taller building is situated behind the shorter one, the dominant stagnation point still resides on the upper portion of the taller downstream building. The downward flow emanating from this point can produce especially intense velocity fluctuations in the space separating the buildings (Britter \& Hunt, 1979; Zajic et al., 2011). If one building towers considerably above the surrounding urban landscape, the effects of the roughness elements surrounding the building diminish as the difference in height becomes greater. Consequently, the resulting flow adjacent to the tall building begins to more closely approximate the previously described flow around an isolated building with a normalized velocity profile and turbulence intensities approaching the values for an isolated building (Abohela et al., 2013). A building with extensive height, such as this, will realize its highest turbulence levels near the top of the building that is embedded in higher speed flow. Street level turbulence will be dictated by the peculiarities of the surrounding urban environment (Zajic et al., 2011).

While prevailing flow in the urban canopy is tempered within canyons, the building canyons can appreciably increase surface-level winds. However, contrary to a commonly held belief, even though an acceleration of the surface winds takes place in both scenarios, surface wind speed amplification is typically greater between diverging versus converging building configurations (Stathopoulos, Blocken, \& Carmeliet, 2008). The perception that a converging channel provides a greater acceleration is often attributed to the Venturi effect. However, this association neglects to realize that urban flow is not a confined flow and is free to move up and over, or around, the associated buildings. This is supported by the observation of Wang et al. that shows for two adjacent buildings, with flat roofs, that flow speed over the roof generally increased in a converging inlet arrangement and decreased for a diverging inlet configuration (Wang, Cot, Adolphe, Geoffroy, \& Morchain, 2015). Diverging canyons are more effective at accelerating the flow because of the wind blocking effect that is more appreciable 
for a converging building configuration (Stathopoulos, Blocken, Moonen, \& Carmeliet, 2008). For a converging building arrangement, the flow is accelerated to a lesser extent as a greater volume of air is captured by the wider opening. Consequently, upstream air, for a considerable distance, is slowed. Downstream flow can emerge as an exit jet but is quickly tempered by mixing with the less energetic flow in the wake of the buildings (Stathopoulos, Blocken, \& Carmeliet, 2008). Regardless of the configuration, a greater acceleration should be anticipated when the upstream flow is more closely aligned with the axis of the canyon, the passage width-to-height ratio decreases, the buildings are shorter in length (Lu \& Ip, 2009), and at the mid to upper level of the buildings ( $\mathrm{Lu} \& \mathrm{Ip}$, 2009; Stathopoulos et al., 2008); but, the magnitude of the acceleration does not show a dependence on the height of the buildings themselves ( $\mathrm{Lu} \& \mathrm{Ip}, 2009$; Stathopoulos et al., 2008). While the increase in speed is realized from the center of the passage outward toward the walls of the buildings (Stathopoulos et al., 2008), for observed inflow between 6 and $8 \mathrm{~m} / \mathrm{s}$, a highly turbulent layer has been shown to exist within $3-3.75 \mathrm{~m}$ of the walls respectively. For building configurations with separations spanning between 10 and $20 \mathrm{~m}$, up to a doubling of the surface wind speed has been realized ( $\mathrm{Lu} \& \mathrm{Ip}, 2009)$. In addition to the aforementioned flow dynamic, additional large vortices should be anticipated within the horizontal plane at the height of canyon edges (Zajic et al., 2011).

At the building roof top level, three-dimensional wind velocity and turbulence characteristics are strongly tied to roof geometry versus building density (Rafailidis, 1997). The amount of acceleration and change in turbulence intensity depend on the roof profile (Figure 3), relative wind direction, and the position on the roof. Of course, flow has to first pass over the roof edge and this transition can also influence the downstream flow behavior. Various roof edge shapes (Figure 4) have been shown to bring about different levels of separation, and associated regions of recirculation, and turbulence. Qualitative and quantitative analysis has shown no substantive difference in the immediate vicinity, or downstream, of the edge of a cantilever style corner relative to a simple building edge. The railing edge on the other hand reduces the mean wind speed but introduces a significant increase in turbulence intensity, along with a recirculation that can extend well beyond the length of the roof (Toja-Silva, Lopez-Garcia, Peralta, Navarro, \& Cruz, 2016). Conversely, the curved edge affords a significant decrease in turbulence and generates a relatively small recirculation region with only a slight increase in wind speed at the upstream edge as the corner smoothly expands the flow (Yang et al., 2016). 


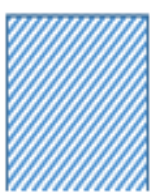

(a)

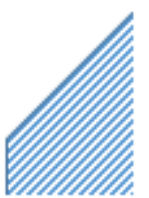

(b)

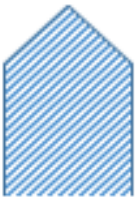

(c)

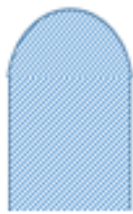

(d)

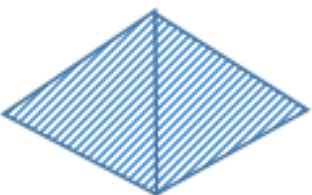

(e)

Figure 3. Roof profiles: a) flat; b) shed; c) pitched; d) vaulted (2-D), spherical (3-D); e) pyramid.

a

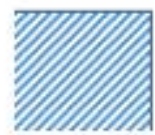

(a)

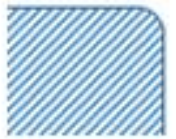

(b)

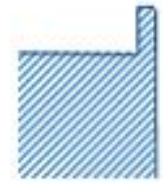

(c)

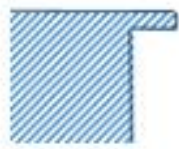

(d)

Figure 4. Cross sections of roof edge shapes: a) simple; b) curved; c) railing; d) cantilever.

Comparable to roof edges, curved roof geometries bring about the greatest increase in flow speed, decrease the intensity of turbulence, and minimize zones of recirculation. This is in contrast to more sharp edge profiles that bring about the opposite flow characteristics. Therefore, the greatest increase in wind speed, and decrease in turbulence intensity, should be anticipated over spherical and vaulted roofs (Abohela et al., 2013; Toja-Silva et al., 2015). Consequently, in general, greater wind velocities, but smaller turbulence intensities, are realized over hip style roofs (all sides slope) than gable roofs (2 sides slope) (Ledo, Kosasih, \& Cooper, 2011; Sari, 2015; Sari \& Kusumaningrum, 2014; Toja-Silva et al., 2015). While all roofs serve to accelerate flow, flat roofs produce the smallest acceleration of the flow and the associated mild increase in turbulence intensity is confined to within close proximity of the roof surface (Abohela, et al., 2013; Rafailidis, 1997) and dissipates very rapidly downstream (Ledo et al., 2011). All other roof geometries, in conjunction with accelerating the flow, increase the magnitude of the turbulence intensity from the edge to the ridge (Ledo et al., 2011) and produce the maximum turbulent layer thickness in the middle of the roof, with the exception of the shed roof. The shed roof style, in contrast, produces the greatest turbulence intensity, and turbulence layer thickness, near the leading edge of the roof when the incline is facing away from 
the approaching flow; when the incline faces the approaching flow, these maximums are located at the trailing edge (Ledo et al., 2011; Lu \& Ip, 2009).

For other pitched roofs, the orientation of the approaching flow relative to the roof's ridge strongly determines the amount of separation. Numerical investigations have shown a three-fold increase in roof-level turbulence in the streamline and vertical directions for such roofs compared to flat roofs (Rafailidis, 1997). The angle of inclination of a pitched roof most strongly impacts the magnitude of the wind speed amplification. Investigations calculating wind velocities for inclination angles between 20 and 50 degrees showed that a roof pitch of 30 degrees generated the maximum average wind speed while a separate investigation demonstrated that a decrease in wind speed was realized for angles greater than 55 degrees (Sari, 2015). While a similar relationship between inclination angle and wind speed is anticipated for pyramid roofs, the separation over a pyramid roof is much smaller in keeping with the general observation of the behavior brought about by hip style, versus gable style, roofs (Ledo et al., 2011).

\section{Conclusion}

The evolution of UAS technology and regulations in a maturing industry is making possible previously unrealized applications and leading to new possibilities. Many of these applications in the future will take place in an urban environment. The urban boundary layer is an especially spatially and temporally dynamic region of the atmosphere and wind and turbulence can, to a greater extent, affect sUAS with their low mass, moment of inertia, and speed. Therefore, in the absence of a significant number of flight hours accumulated within the urban environment, this paper extracts relevant insight from studies on sUAS disturbance rejection and urban flow. An explicit reiteration of the most significant insight or important features of urban flow related to sUAS operations are:

- The turbulence intensity that an UA perceives decreases with increasing flight speed.

- In general, at low altitudes, turbulence intensity in suburban environments has been found to be twice as high as in rural settings. High rise city centers can offer three times the turbulence intensity found in rural settings.

- Smaller eddies with temporal scales on the order of seconds are of greatest concern for sUAS.

- Multirotor aircraft are less susceptible to the effects of turbulence than their fixed-wing counterpart but highly turbulent conditions can exceed the capability of both category of UA. 
- While low disk loading improves an UA's efficiency and endurance, it makes it more susceptible to turbulence.

- Multirotor and fixed-wing UA are most sensitive to atmospheric disturbance about the longitudinal axis (roll) but correcting from this type of disturbance is the least energy intensive.

- UA are most susceptible to turbulence with a wavelength of approximately one-half the aircraft's wingspan. These perturbations in the flow bring about spanwise variation in angle of attack that produce the largest moments.

- While conducting an urban operation, disturbed flow can exist up to a height of three times that of the tallest structure.

- Compared to the streamwise direction, turbulence is weaker in the crossstream direction and least intense in the vertical direction and areas of upward air movement.

- Regions of reverse flow and relatively low wind speed exist upstream of buildings. An increase in building height or width does not displace the location of such a region found immediately in front of the building but an increase in either of these building dimensions displace such a region further upstream.

- Separated flow on the sides and downwind of a building can greatly accelerate the flow around buildings while concurrently creating regions of suction and reverse flow.

- As building height increases, the near-surface recirculation regions characterized by low wind speed but high turbulence decrease in size. However, the reattachment length for separated flow at the top of the building increases. For each of these regions, the magnitude of the turbulence intensity scales with building height.

- Building configurations with a high aspect ratio, stemming from close building spacing, establish a more stable vortex in the inter-building space with the majority of the flow passing overhead.

- Building configurations with an intermediate aspect ratio produce a robust area of recirculation between the buildings enhanced by downward flowing air on the windward face of the downwind building.

- A building array with a lower aspect ratio has a wider and more robust reverse flow region within the inter-building spacing.

- An attenuation of prevailing canopy flow in the center of an urban canyon as great as $50 \%$ has been observed for flow approaching the canopy in line with its major axis; an attenuation as great as $75 \%$ has been observed in the center of the canyon for a perpendicular approach angle.

- When a shorter building is positioned behind a significantly taller one, the wake of the taller building dominates the entire wake structure. 
- When a taller building is situated behind a shorter one, especially intense velocity fluctuations can occur in the space separating the buildings.

- Contrary to what is often maintained, surface wind speed amplification is typically greater between diverging than converging building configurations.

- Observations of canyon flow for inflow speeds between 6 and $8 \mathrm{~m} / \mathrm{s}$ have shown a turbulent layer adjacent to the building walls between $3-3.75 \mathrm{~m}$ thick.

- Roof top level winds and turbulence show more of a dependency on roof geometry than building aerial density.

- Roof edge shape can significantly influence flow behavior over the roof.

- Curved roof geometries bring about the greatest increase in flow speed, decrease the intensity of turbulence, and minimize zones of recirculation.

- The angle of inclination of a pitched roof predominately determines the magnitude of the wind speed amplification. A pitch of 30 degrees produces the greatest increase in flow speed and inclinations greater than 55 degrees have been shown to decrease the wind speed. 


\section{References}

Abd Razak, A., Hagishima, A., Ikegaya, N., \& Tanimoto, J. (2013). Analysis of airflow over building arrays for assessment of urban wind environment. Building \& Environment, 59, 56-65. doi:10.1016/j.buildenv.2012.08.007

Abdulrahim, M., Watkins, S., Segal, R., Marino, M., \& Sheridan, J. (2010). Dynamic sensitivity to atmospheric turbulence of unmanned air vehicles with varying configuration. Journal of Aircraft, 47(6), 1873-1883. doi: $10.2514 / 1.46860$

Abohela, I., Hamza, N., \& Dudek, S. (2013). Effect of roof shape, wind direction, building height $\&$ urban configuration on the energy yield \& positioning of roof mounted wind turbines. Renewable Energy, 50, 1106-1118. doi:10.1016/j.renene.2012.08.068

Anderson, J. D., Jr. (2017). Fundamentals of aerodynamics (6th ed.). New York, NY: McGraw Hill Education.

Bowne, N. E., \& Ball, J. T. (1970). Observational comparison of rural \& urban boundary layer turbulence. Journal of Applied Meteorology (1962-1982), 9(6), 862-873. doi:10.1175/1520-0450

Britter, R. E., \& Hanna, S. R. (2003). Flow \& dispersion in urban areas. Annual Review of Fluid Mechanics, 35(1), 469-496. doi:10.1146/annurev.fluid.35.101101.161147

Britter, R. E., \& Hunt, J. C. R. (1979). Velocity measurements \& order of magnitude estimates of the flow between two buildings in a simulated atmospheric boundary layer. Journal of Wind Engineering \& Industrial Aerodynamics, 4(2), 165-182. doi.org/10.1016/0167-6105(79)90044-8

Chen, Y., He, Y., \& Zhou, M. (2013). Modeling \& control of a quadrotor helicopter system under impact of wind field. Research Journal of Applied Sciences, Engineering and Technology, 6(17), 3214-3221.

Ching, J. K. S. (1985). Urban-scale variations of turbulence parameters \& fluxes. Boundary-Layer Meteorol, 33, 335. doi.org/10.1007/BF00116683

Clarke, C., Ching, J., \& Godowich, J. (1982). A study of turbulence in an urban environment. In EPA Technical Report, EPA 600-S3-82-062.

Counehan, J. (1967). Wind tunnel determination of the roughness length as a function of a fetch $\&$ the roughness density of three-dimensional roughness elements. Atmospheric Environment, 5, 637-642.

Etkin, B. (2005). Dynamics of atmospheric flight. Mineola, NY: Dover.

Erell, E., Pearlmutter, D., Williamson, T., \& Williamson, T. (2015). Urban microclimate: Designing the spaces between buildings. Retrieved from https://www.researchgate.net/publication/255989068_Urban_Microclimat e_-_Designing_the_Spaces_Between_Buildings. 
Heath, M. A., Walshe, J. D., \& Watson, S. J. (2007). Estimating the potential yield of small building-mounted wind turbines. Wind Energy, 10(3), 271287. doi:10.1002/we.222

Hosker, R. P. (1979). Empirical estimation of wake cavity size behind block type structures. Presented at 4th Fourth Symposium on Turbulence, Diffusion \& Air Pollution. Reno, NV: American. Metrological Society.

Hunt, J. C. R., \& Carruthers, D. J. (2004). Urban accidental releases review. Cambridge Environmental Research Consultants Report for ADMC, Rep. FM568/R1/03.

Hussain, M., \& Lee, B. E. (1980). A wind tunnel study of the mean pressure forces acting on large groups of low-rise buildings. Journal of Wind Engineering \& Industrial Aerodynamics, 6(3/4), 207-225. doi.org/10.1016/0167-6105(80)90002-1

Kennedy, J., Fisher, A., Wang, L., \& Palmer, J. L. (2017). Effects of actuator dynamics on disturbance rejection for small multi-rotor UAS. Paper presented at the 2017 Australian and New Zealand Control Conference (ANZCC),116-121. doi:10.1109/ANZCC.2017.8298496.

Lawson, R. E., W. Snyder, \& Hunt, J. (2002). Flow structure of recirculating wake flows downwind of surface mounted obstacles. Washington, D.C.: U.S. Environmental Protection Agency, EPA/600/D-88/065 (NTIS PB88195987).

Ledo, L., Kosasih, P. B., \& Cooper, P. (2011). Roof mounting site analysis for micro-wind turbines. Renewable Energy, 36(5), 1379-1391. doi:10.1016/j.renene.2010.10.030

Lissaman, P. (2009). Effects of turbulence on bank upsets of small flight vehicles. doi:10.2514/6.2009-65

Loxton, B., Abdulrahim, M., \& Watkins, S. (2008). An investigation of fixed \& rotary wing MAV flight in replicated atmospheric turbulence. doi:10.2514/6.2008-227

Lu, L., \& Ip, K. Y. (2009). Investigation on the feasibility \& enhancement methods of wind power utilization in high-rise buildings of Hong Kong. Renewable \& Sustainable Energy Reviews, 13(2), 450-461. doi:10.1016/j.rser.2007.11.013

Marino, M., Fisher, A., Clothier, R., Watkins, S., Prudden, S., \& Leung, C. S. (2015). An evaluation of multi-rotor unmanned aircraft as flying wind sensors. International Journal of Micro Air Vehicles, 7(3), 285-299. doi:10.1260/1756-8293.7.3.285

Mohamed, A., Carrese, R., Fletcher, D. F., \& Watkins, S. (2015). Scale-resolving simulation to predict the updraught regions over buildings for MAV orographic lift soaring. Journal of Wind Engineering \& Industrial Aerodynamics, 140, 34-48. doi:10.1016/j.jweia.2015.01.016 
Mohamed, A., Clothier, R., Watkins, S., Sabatini, R., \& Abdulrahim, M. (2014). Fixed-wing MAV attitude stability in atmospheric turbulence, part 1: Suitability of conventional sensors. Progress in Aerospace Sciences, 70, 69-82. doi:10.1016/j.paerosci.2014.06.001.

Mohamed, A., Massey, K., Watkins, S., \& Clothier, R. (2014). The attitude control of fixed-wing MAVS in turbulent environments. Progress in Aerospace Sciences, 66, 37-48. doi:10.1016/j.paerosci.2013.12.003.

Nelson, R. C. (1998). Flight stability \& automatic control (2nd ed.). Boston, MA: WCB/McGraw Hill.

Oke, T. R. (1987). Boundary layer climates. New York, NY: Psychology Press.

Oke, T. R. (1988). Street design \& urban canopy layer climate. Energy \& Buildings, 11(1-3), 103-113. doi.org/10.1016/0378-7788(88)90026-6

Pearlmutter, D., Berliner, P., \& Shaviv, E. (2005). Evaluation of urban surface energy fluxes using an open-air scale model. Journal of Applied Meteorology, 44(4), 532-545. doi:10.1175/JAM2220.1

Prudden, S., Fisher, A., Marino, M., Mohamed, A., Watkins, S., \& Wild, G. (2018). Measuring wind with small unmanned aircraft systems. Journal of Wind Engineering \& Industrial Aerodynamics, 176, 197-210. doi:10.1016/j.jweia.2018.03.029.

Rafailidis, S. (1997). Influence of building areal density \& roof shape on the wind characteristics above a town. Boundary-Layer Meteorology, 85(2), 255271. doi:10.1023/A:1000426316328

Raupach, M. R., Thom, A. S., \& Edwards, I. (1980). A wind-tunnel study of turbulent flow close to regularly arrayed rough surfaces. Boundary-Layer Meteorology, 18, 373. doi.org/10.1007/BF00119495

Rotach, M. W. (1993a). Turbulence close to a rough urban surface. Part I:

Reynolds stress. Boundary-Layer Meteorology, 65. doi.org/10.1007/BF00708816

Rotach, M. W. (1993b). Turbulence close to a rough urban surface. Part II: variances \& gradients. Boundary-Layer Meteorology, 66. doi.org/10.1007/BF00705460

Roth, M. (2000), Review of atmospheric turbulence over cities. Quarterly Journal of the Royal Meteorological Society, 126, 941-990. doi:10.1002/qj.49712656409

Sari, D. P. (2015). Measurement of the influence of roof pitch to increasing wind power density. Energy Procedia, 65, 42-47. doi:10.1016/j.egypro.2015.01.029

Sari, D. P., \& Kusumaningrum, W. B. (2014). A technical review of building integrated wind turbine system \& a sample simulation model in Central Java, Indonesia. Energy Procedia, 47, 29-36. doi:10.1016/j.egypro.2014.01.193 
Schmid, H.P., Cleugh, H.A., Grimmond, C.S.B., \& Oke, T.R. (1991). Spatial variability of energy fluxes in suburban terrain. Boundary-Layer Meteorology, 54, 249. doi.org/10.1007/BF00183956

Stathopoulos, T., Blocken, B., \& Carmeliet, J. (2008). Wind environmental conditions in passages between two long narrow perpendicular buildings. Journal of Aerospace Engineering, 21(4), 280-287. doi:10.1061/(ASCE)0893-1321(2008)21:4(280)

Stathopoulos, T., Blocken, B., Moonen, P., \& Carmeliet, J. (2008). Numerical study on the existence of the venturi effect in passages between perpendicular buildings. Journal of Engineering Mechanics, 134(12), 1021-1028. doi:10.1061/(ASCE)0733-9399(2008)134:12(1021)

Stevens, B. L., \& Lewis, F. L. (2003). Aircraft control and simulation (2nd ed.). Hoboken, N.J: J. Wiley.

Stull, R. B. (1988). An introduction to boundary layer meteorology. Netherlands: Kluwer Academic Publishers. doi: 10.1007/978-94-009-3027-8

Sydney, N., Smyth, B., \& Paley, D. A. (2013a). Dynamic control of autonomous quadrotor flight in an estimated wind field. Paper presented at the 36093616. doi:10.1109/CDC.2013.6760438

Sydney, N., Smyth, B., \& Paley, D. A. (2013b). Wind disturbance estimation and rejection for quadrotor position control. Paper presented at the IEEE 52nd Annual Conference on Decision and Control.

Szczublewski, D. P. (2012). Gust disturbance analysis of a micro quadrotor helicopter. Retrieved from http://hdl.handle.net/1903/12810

Thompson, M. (2012). The small scales of turbulence in atmospheric winds at heights relevant to MAVS. Retrieved from https://researchbank.rmit.edu.au/view/rmit:160453

Thompson, M., \&Watkins, S. (2010). Gust inputs relevant to bees, birds, and MAVs. Proceedings of the 25th UAVS Conference, University of Bristol.

Thompson, M., Watkins, S., White, C., \& Holmes, J. (2011). Span-wise wind fluctuations in open terrain as applicable to small flying craft. The Aeronautical Journal, 115(1173), 693-701. doi:10.1017/S0001924000006412

Toja-Silva, F., Lopez-Garcia, O., Peralta, C., Navarro, J., \& Cruz, I. (2016). An empirical-heuristic optimization of the building-roof geometry for urban wind energy exploitation on high-rise buildings. Applied Energy, 164, 769-794. doi:10.1016/j.apenergy.2015.11.095

Tran, N. K., Bulka, E., \& Nahon, M. (2015). Quadrotor control in a wind field. Paper presented at the 2015 International Conference on Unmanned Aircraft Systems, ICUAS 2015320-328. doi:10.1109/ICUAS.2015.7152306 
Tsang, C. W., Kwok, K. C. S., \& Hitchcock, P. A. (2012). Wind tunnel study of pedestrian level wind environment around tall buildings: Effects of building dimensions, separation and podium. Building and Environment, 49, 167-181. doi:10.1016/j.buildenv.2011.08.014

Walshe, D. E. J. (1972). Wind-excited oscillations of structures. NPL Monograph. doi:10.1017/S0001924000044286.

Wang, B., Cot, L. D., Adolphe, L., Geoffroy, S., \& Morchain, J. (2015). Estimation of wind energy over roof of two perpendicular buildings. Energy and Buildings, 88, 57-67. doi:10.1016/j.enbuild.2014.11.072

Watkins, A., Thompson, M., Shortis, M., Segal, R., Abdulrahim, M., \& Sheridan, J. (2010). An overview of experiments on the dynamic sensitivity of MAVs to turbulence. The Aeronautical Journal, 114(1158), 485-492. doi:10.1017/S0001924000003973

Watkins, S., Milbank, J., Loxton, B. J., \& Melbourne, W. H. (2006). Atmospheric winds and their implications for microair vehicles. AIAA Journal, 44(11), 2591-2600. doi:10.2514/1.22670

Watkins, S., Thompson, M., Loxton, B., \& Abdulrahim, M. (2010). On low altitude flight through the atmospheric boundary layer. International Journal of Micro Air Vehicles, 2(2), 55-68. doi:10.1260/1756-8293.2.2.55

Yang, A., Su, Y., Wen, C., Juan, Y., Wang, W., \& Cheng, C. (2016). Estimation of wind power generation in dense urban area. Applied Energy, 171, 213230. doi:10.1016/j.apenergy.2016.03.00

Yeo, D., Sydney, N., \& Paley, D. A. (2016). Onboard flow sensing for rotarywing UAV pitch control in wind. doi:10.2514/6.2016-1386

Zajic, D., Fernando, H. J. S., Brown, M. J., \& Pardyjak, E. R. (2015). On flows in simulated urban canopies. Environmental Fluid Mechanics, 15(2), 275303. doi:10.1007/s10652-013-9311-6

Zajic, D., Fernando, H. J. S., Calhoun, R., Princevac, M., Brown, M. J., and Pardyjak, E. R. (2011). Flow and turbulence in an urban canyon. Journal of Applied Meteorology and Climatology, 50(1), 203-223. doi:10.1175/2010JAMC2525.1 